\title{
ALGO MÁS SOBRE ROMANCES (Y CANCIONES) EN ENSALADAS
}

En el número 1 de la revista $E l$ Crotalón se publicó un valioso artículo de la profesora Giuliana Piacentini sobre los romances citados en diversas ensaladas de la segunda mitad del siglo XV1 y comienzos del XVII ${ }^{1}$.

No es necesario insistir en el interés de este tipo de trabajos, por desgracia hasta ahora bastante escasos. En primer lugar porque - como señala Piacentini- nos permiten hacernos una idea de cuáles eran los romances (y canciones) más conocidos y apreciados por el público de los Siglos de Oro, cosa que no siempre podemos calibrar sólo a través de las colecciones impresas conservadas.

De paso, ese conocimiento del "repertorio" de la época nos permite entender no pocas de las alusiones intertextuales que salpican toda la literatura de los siglos XVI y XVII. Así, la proliferación de citas de Belerma ${ }^{2}$ en ensaladas nos ayuda a comprender por qué es ése precisamente el romance que parodia Cervantes en el episodio de la Cueva de Montesinos: su presencia recurrente en ensaladas nos confirma que se trataba de un romance muy conocido, que estaba en boca de todos, y de ahí que cualquier lector estuviese capacitado para entender la broma que sirve de sustento a ese capítulo del Quijote (II.23). Del mismo modo se explica que Cristóbal de Castillejo escogiese precisamente el romance de La infanta seducida ${ }^{3}$ (que aparece en varias ensaladas)

1 “Romances en ensaldas y géneros afines", El Crotalón. Anuario de Filología Española, 1 (1984), 1135-1173. Sobre el género de la ensalada hace interesantes observaciones Frenk 1989 en su edición de las obras de González de Eslava: véanse especialmente las pp. 80-84.

${ }^{2}$ Es el romance que empieza "Oh Belerma, oh Belerma, / por mi mal fuiste engendrada". Puede verse una versión en Primavera, núm. 181.

${ }^{3}$ Es el que empieza “Tiempo es, el caballero, / tiempo es de andar de 
como base para un irónico y amargo contrafactum en que el poeta viejo se lamenta de su mala fortuna en la corte. Ejemplos como éstos podrían ponerse muchos más.

No olvidemos, por otra parte, que cuando hablamos de lo que el público conocía y apreciaba, no sólo nos referimos a lo que leía, sino también a lo que se sabía de memoria, por ejemplo, por haberlo aprendido a cantar. La gracia de las ensaladas radicaba precisamente en esto: en el reconocimiento de citas de poemas que estaban en la memoria del público destinatario. Algunas de esas citas nos transmiten indirectamente noticias sobre la vida oral de determinados temas romancísticos y cancioneriles, bien aportando variantes con respecto a las fuentes impresas y manuscritas contemporáneas, bien documentando en los Siglos de Oro temas o formulaciones que - aparezcan o no en otras fuentes escritas - han pervivido en la tradición oral moderna.

No todas las citas han podido ser identificadas en su artículo por la profesora Piacentini; quien, por otra parte, ha dejado deliberadamente al margen las que no corresponden a romances, sino a otros géneros. Siguiendo su propia invitación ${ }^{4}$, nos atrevemos a intentar la identificación de algunas de las entradas de la lista alfabética de "no identificados" inserta al final de artículos, atendiendo esta vez tanto a los versos romancísticos como a poemas de otros tipos. Las agrupamos según su interés en:

aquí", núm. 158 de Primavera. Para el romance y el contrafactum de Castillejo véase Díaz-Mas 1988.

4 "No siempre el intento de identificar los romances relacionados con las citas ha tenido éxito; en algunos casos (que indico con asteriscos) he creído posible, según huellas contenidas en los versos mismos, atribuirlos a un ciclo temático. Cuando ni aun esto ha sido posible, he eliminado los versos desconocidos de los materiales de mi investigación, reuniéndolos en una lista sobre la que, espero, otros estudiosos puedan practicar con mejor éxito su erudición" (p. 1136). De esa lista excluye algunas citas no romancísticas que ya fueron identificadas por BERNADACH 1973 en su artículo sobre el poema de Castillo Solórzano A la fuerça de Lucrecia: "Yo que lo sé que lo vi se lo digo. . ." (canción citada en un entremés y una obra de Calderón: véase ahora Frenk 1987, núm. 1518) y "Esto que me abrasa el pecho / no es posible que es amor" (cita de La Arcadia de Lope).

${ }^{5}$ Añádase a ello una precisión sobre el número 121 de la lista de versos reconocidos por Piacentini: "Xerez, aquesta nombrada, / cercada está de christianos", del cual indica "¿Tema Histórico-Fronterizo?" (p. 1159), es en efecto un romance de ese ciclo temático, que está en la colección de Durán con el número 933, bajo el epígrafe "Cerco de Jerez, donde Diego Pérez de Vargas gana el apellido de Machuca" y con las variantes "Jerez, aquesa nombrada / cercada era de cristianos". 
1. Composiciones documentadas en fuentes antiguas (de los siglos XV al XVII):

la. Las que aparecen con idénticas formulaciones en impresos y manuscritos de los siglos XV al XvII.

1b. Casos en que la cita de la ensalada presenta variantes con respecto a las versiones impresas o manuscritas que nos han llegado.

le. Composiciones de las que nos han llegado otros textos de los siglos XV al XVII y que han pervivido en la tradición oral hasta época moderna.

2. Composiciones que no aparecen en otras fuentes antiguas:

2a. Las que debieron gozar de popularidad en su momento, pero de las que no se nos han conservado textos.

2b. Composiciones de las que no se conservan textos antiguos, pero sí tradicionales modernos.

\section{Composiciones documentadas en fUentes antiguas (DE LOS SIGLOS XV AL XVII)}

1a. Las que aparecen con idénticas formulaciones en impresos y manuscritos de los siglos XV. al XVII.

la.1. "Ardiéndose estaba Troya / torres, cimientos y almenas", del poema $A$ la fuerça de Lucrecia de Castillo Solórzano (1625), es el inicio de uno de los ocho romances que habían sido incluidos en el Quinto quaderno de varios romances... impreso en Valencia en 1593 y aparece también en otro pliego sevillano sólo un poco posterior 6 .

la.2. "Canta tu christiana musa / la más que ciuil batalla", que aparece en la Glosa peregrina (1560) es, naturalmente, el inicio de las Coplas contra los pecados mortales o Disputación de vicios de Juan de Mena, obra de amplia difusión tanto manuscrita como impresa: está en no menos de dieciséis manuscritos y en siete ediciones antiguas de la obra de Mena; pero además alcanzó difusión en pliegos sueltos: se incluyó en uno de los pocos pliegos incunables que se conservan (de Salamanca, 1500 y hoy en la British Library) y en otro sin año actualmente en la Hispanic Society de Nueva York ${ }^{7}$.

${ }^{6}$ Referencia en Rodríguez MoÑino 1970, p. 657 y Cátedra e Infantes 1983, pliego 4.

${ }_{7}$ Para la difusión manuscrita y las ediciones en la obra de Mena, véase 
1a.3. "Entre Torres y Ximena / saliendo de vn allozar", del Tercero quaderno (entre 1594 y 1598): cita una serranilla del Marqués de Santillana ("Entre Torres y Canena / acerca de Sallozar'), que a su vez fue glosada por Gonzalo de Montalbán e impresa con su glosa en media docena de pliegos sueltos ${ }^{8}$.

la.4. "Lágrimas que no pudieron / tanta dureza ablandar", también del poema de Castillo Solórzano: debió ser canción muy del gusto del público de finales del siglo xvı y principios del XVII, ya que aparece impresa en el Ramillete de flores: Qvarta, Quinta y Sexta parte de Flor de romances nueuos, de Pedro de Flores (Lisboa, 1593); se reimprimió con la Sexta parte en Toledo (1594), Alcalá (1595 y 1597) y Zaragoza (1596); y se incluyó en el Romancero general (eds. de 1600 y 1602). Además, la utiliza Gimés Pérez de Hita en sus Guerras civiles de Granada, poniéndola en boca de un caballero moro quien, según él, "cantó en arábigo esta sentida canción", 9

la.5. "Las tristes lágrimas mías / en piedras hazen señal", que aparece en la Glosa peregrina, debió ser villancico muy conocido al menos desde comienzos del siglo xvı, a juzgar por su ubicuidad: está en el cancionero musical de Elvas (ha. 1520) y en otro de la Biblioteca de Palacio de Madrid (compilado ha. 15601570), donde se incluye además una glosa que comienza "La gota solemos ver', atribuida a Burguillos, glosa que aparece a su vez en otro manustrico de la Biblioteca Nacional de Madrid; se cita como lema de una cimera de justas en un cancionero manuscrito de la British (ha. 1500). Y más tardíamente aparecen glosas en el Cancionero de Fuenmayor (comienzos del siglo XVII) y en un cancionero de jesuitas (último cuarto del siglo XVI): en el primero la glosa comienza "Tus misericordias canto", y en el segundo se incluye la misma y además otra de tono humorístico dedicada a una sotana rota ("La culpa vos la tenéis / sotana de estar así").

Más prolífica aún fue su vida impresa, donde aparece como letra de diversas glosas de muy distinto tono: desde la amorosa

Dutton 1982, núm. 0100, así como los textos en Dutton 1990. Para la difusión en pliegos, cf. RoDríGuez MoÑino 1970, p. 660; véase también sobre los pliegos incunables Infantes 1989: el que contiene nuestro poema es el núm. VII, p. 96.

${ }^{8}$ Para los pliegos, cf. Rodríguez Moñino 1970, p. 674; para los manuscritos con el poema de Santillana, DutTon 1982, núm. 3433.

9 Para las referencias de ediciones, véase Rodríguez MoÑino 19731978, t. 2, p. 549. El uso por Pérez de Hita lo comenta Menéndez Pidal 1953 , t. 2, p. 34 . 
“Muera, muera, que's razón” de sendos pliegos hoy en la British y en la Biblioteca Nacional de Madrid, hasta una "en disparates" que comienza "En unos montes espesos" (en un pliego de Praga), sin que pudiera faltar la casi obligada glosa a lo divino ("Alma no seas tan esquiua", en un pliego de la British impreso en Barcelona en 1600).

También proliferan las glosas del villancico en colecciones impresas del siglo xvi: la misma "Muera, muera..." se incluyó en la Segunda parte del Cancionero general (Zaragoza, 1552), pero antes se había incluido otra, que empieza "Qualquier pena interior / vençe cualquiera de fuera', en el gótico Cancionero de Velázquez de Avila. Y después siguieron floreciendo en profusa eclosión: en el Cancionero general de obras nuevas . . (Zaragoza, 1554) aparece la que empieza "Quando remedio sespera / de vn amoroso accidente"; en las ediciones del Cancionero general hechas por Martín Nucio (1557) y su hijo Philipo (1573) está con la glosa "Ando tan apesarado"; en la Flor de romances de Zaragoza 1578 hay otra que comienza "Amor poco ha aprouechado / vuestro fuego en mi favor' ; y Juan López de Úbeda incluyó una más en su Cancionero general de la doctrina christiana, al menos en sus ediciones de 1585 y 1586. La profusión de glosas de muy diverso tono (amoroso, religioso, humorístico) en las distintas fuentes nos indica qué variedad de lecturas podía tener un mismo texto en el siglo XV ${ }^{10}$.

la.6. "Nunca fue pena mayor / ni tormento tan estraño", de la Glosa peregrina, es un caso típico de pervivencia en el gusto del siglo XVI de una composición del xv; está documentadísima en cancioneros manuscritos del siglo $\mathrm{xv}$, en cinco de los cuales aparece como anónima y en otros tres atribuida a Juan Urrede; hay una traducción al italiano incluida en un manuscrito hoy en el conservatorio de Florencia y posteriormente impresa en Venecia; su incipit aparece en no menos de diez manuscritos y varias ediciones italianas de libros de música; Garci Sánchez de Badajoz pone esos versos en boca de Sancho de Castilla en su famoso poema citador Infierno de amor; Jerónimo Pinar incluye su inicio en su Juego de naipes. Hay también un par de glosas en manuscritos: la que comienza "Sin remedio de mi venir' (en un cancionero de Nápoles, 1486) y "Serviros y contentaros" en otro (copia del

${ }^{10}$ Para las versiones manuscritas véanse DutTon 1982, núm. 0977; Blecua 1983, núm. 77 y Rodríguez Moñino 1969, p. 230. Para pliegos, RodRíGuez MoNino 1970, p. 680; y para colecciones impresas, RodRíGueZ MoÑlNo 1973-1978, t. 2, p. 559. 
siglo xviII) de la Biblioteca Nacional de Madrid. Sin duda contribuyó a mantener vigente la composición su inclusión (con una glosa del Comendador Román que empieza "Alta reina esclarescida") en el Cancionero general de 1511 y sus sucesivas reediciones hasta $1573^{11}$.

1a.7. "Oyga tu merced y crea / hay de quien nunca te vido", de la misma Glosa peregrina, constituye un caso semejante al anterior: la aparición más antigua parecé ser la de un manuscrito de ha. 1470 conservado en la Biblioteca Marciana de Venecia, donde se incluyen la composición y una glosa ("Corona de las mejores"). Se encuentra también como anónima en otros tres manuscritos, entre ellos el Cancionero musical de Palacio; uno de la British (ha. 1500) lo atribuye a Tapia, junto con la misma glosa que el de la Marciana; en uno de Madrid (1560-1570) aparece atribmido a don "Pedro, Duque de Nájera"; mientras que otro de Salamanca lo adjudica a Juan de Mena, entre cuyas obras impresas en Sevilla por Cromberger aparece también.

Como en el caso anterior, debió de ser el Cancionero general de Hernando del Castillo pieza clave para su difusión en el siglo Xvi: allí aparece junto con la ya conocida glosa "Corona de las mejores", atribuido a Tapia como en el manuscrito de la British. Lo mismo incluyó Juan Fernández de Constantina en su Cancionero llamado Guirlanda esmaltada (s.a., aunque posterior al General).

Pero su difusión impresa no se limitó al Cancionero general y a la Guirlanda que le secunda: está en el pliego de Madrid Proverbios en rima del sabio Salomón ... junto con la glosa a lo divino "Consuelo de los nacidos" de Diego Pegera; la misma glosa se imprimió también en otros tres pliegos, en la curiosa compañía del romance del Conde Dirlos, y tal vez estuviera en un pliego que perteneció a Hernando Colón y cuyo contenido se describe en el Abecedarium como una "Canción de $\mathrm{N}^{\mathrm{a}} \mathrm{S}$ a" de "Jacobus Pegera"12.

la.8. "Pastorcico amigo / que auedes que", del Tercero quaderno (entre 1594 y 1598) es composición también citada en la ensalada de Praga, y cuya melodía hubo de ser muy conocida, a juzgar por cómo proliferan en impresos del siglo XVI composiciones "al tono de": en un pliego de Coplas hechas por Christóual

11 Para la presencia en manuscritos; véase DutToN 1982, núm. 0670; para su inclusión en el Cancionero general, RoDRíGuez MoÑINO 1973-1978, t. 2 , p. 631.

${ }^{12}$ Para las apariciones en manuscritos, cf. DutTon 1982, núm. 1051; para pliegos, RoDríguez Moñino 1970, p. 689; y para colecciones, RoDRíGUEZ Moñino 1973-1978, t. 2, p. 649. 
de Pedraza de ha. 1515-1520 (hoy en Oporto) hay un contrafactum a lo divino "Ay, hijo bendito, / que auedes, que"; lo mismo se incluía en unas Coplas de la passión de nuestro señor (ha. 1540), pliego hoy perdido que perteneció a Salvá: en otro pliego de Coplas nueuas fechas por Enrique de Oliua (hoy en Madrid) hay una "desecha al tono de...' que comienza "Nueuas de gozar". Y, ya en el siglo XVII, está el mismo "Ay, hijo bendito" en un pliego impreso en Barcelona (1615) y Francisco de Ocaña incluye en un Cancionero para cantar la noche de Nauidad.(1603) el contrafactum " $\mathrm{Mi}$ gallejo hermano / que te contare"'.

No nos es posible de momento establecer las posibles relaciones entre ese "Pastorcico" tan contrahecho y el villancico "Pastorcico amigo / que los amores has / que ahora morirás" del Cartapacio de Padilla ${ }^{13}$.

la.9. "Salgan las palabras mías / sangrientas del coraçón", de la Glosa peregrina, aparece glosado ("Pues de muerto y consumido') unos años antes en la Segunda parte del Cancionero general (Zaragoza, 1552); con la misma glosa fue incluido en sendos pliegos hoy en la Biblioteca Nacional de Madrid y en la British; y en otro de la Nacional se atribuye a Garci Sánchez de Badajoz ${ }^{14}$.

la.10. "Tiempo bueno tiempo bueno / quién te me apartó de mí', citado en cinco ensaladas (de entre 1550 y fines del siglo XVI) es otro caso claro de vigorosa pervivencia de un tema del siglo xv: la noticia más antigua parece ser un fragmento en italiano de un manuscrito de la abadía de Montecassino (1480), pero está también (atribuido a Flecha) en un manuscrito de la Biblioteca de Cataluña de ha. 1500; como anónimo aparece, acompañado de sendas glosas, en un cancionero de la Biblioteca de Palacio de Madrid de ha. 1560-1570 (con la glosa -incompleta- de Burguillos "Oh triste ventura mía') y en el Cancionero 'general de García de Resende (con "Los tiempos atrás pasados"). En sendos pliegos de Praga y Madrid está glosado por Francisco de Marquina ("Por la gloria antepassada") y en otro de la British le acompaña la glosa “O vida de mi penar'. Está también en el Cancionero de Velázquez de Ávila, cómo no, también glosado ("O engañosa e inconstante / ciega fortuna a mi ver'”). En este como

13 Véase para los pliegos Rodríguez MoÑino 1970 , p. 690 y para el cancionero de Francisco de Ocaña, Rodríguez MoÑino 1973-1978, t. 4, p. 191. Para el villancico en manuscrito, Dutton 1982, núm. 4267. Además, Frenk 1987, núm. 323.

14 Véanse Rodríguez Moñino 1970, p. 699 y 1973-1978, t. 2, p. 733. 
en otros casos el furor por glosar parece haber sido elemento indispensable para la pervivencia de la composición ${ }^{15}$.

la.11. "Una hija de Sant Ana / llamada Virgen María ", de la Glosa peregrina es composición incluida en el ya mencionado pliego suelto Coplas nueuas fechas por Enrique de Oliua de la Biblioteca Nacional de Madrid. Margit Frenk lo identifica como contrafactum a lo divino de una composición cuyo incipit es "Abrasme tú, el hermitaño", que a su vez recuerda formulaciones romancísticas ${ }^{16}$.

la.12. Mención aparte merecen dos entradas de la lista de no identificados: "Do cantaua vn ahorcado / viue Leda si podrás", (de los Disparates de Gabriel de Sarauia, 1550) y “Muy ufano está cantando / biue Leda si podrás"' (de la Vida del estudiante pobre, 1593). Independientemente de que en ambas citas parece haberse confundido - a juzgar por la versalización de las fuentes - leda 'alegre' con Leda (la del cisne), el segundo verso es el inicio de una muy conocida composición de Juan Rodríguez del Padrón que encontramos en una decena de cancioneros manuscritos, incluido el de Estúñiga. Además, lo citan Garci Sánchez de Badajoz en su Infierno de amor, Jerónimo Pinar en su Juego de naipes, Gómez Manrique en su poema "Pues mi contraria fortuna" y Costana en "Al tiempo que se levanta". Y, como no podía ser menos, hay varias glosas: en manuscritos, una en prosa debida al comendador Stela, otra en verso de Burguillos ("Pues temor de enojarte"); y en las ediciones del Cancionero 'general de Hernando del Castillo se incluye (a partir de 1514) la de Luis del Castillo "Pues a mí desconsolado", mientras que en las de 1557 y 1573 aparece otra glosa: "Vaya la pena de entramos"'17.

1b. Casos en que la cita de la ensalada presenta variantes con respecto a las versiones impresas o manuscritas que nos han llegado. La mayoría de los romances y canciones citados en ensaladas no debieron limitar su difusión a la transmisión escrita, sino que se cantarían, se recitarían y, desde luego, los autores de ensaladas y sus lectores

15 Véanse Dutton 1982, núm. 1991 y Blecua 1983, núm. 93; RodríGuez Moñino 1970, p. 703; 1973-1978, t. 2, p. 779.

16 Para el pliego, cf. Rodríguez Moñino 1970, p. 704. Véase Frenk 1987, núm. 2205. La formulación "Dígasme tú, el ermitaño", aparece por ejemplo en el romance de Lanzarote y el ciervo de pie blanco (Primavera, núm. 147).

17 Dutton 1982, núm. 0125; Rodríguez Moñino 1973-1978, t. 2, pp. $679-680$ y 811 . 
los tenían bien presentes en la memoria ${ }^{18}$. Por eso no es de extrañar que varias citas de las ensaladas presenten variantes con respecto a otras versiones impresas. En un buen puñado de números de su lista $(4,30,41-45,63,65,67-68,70,77,84,87-90$, etc.) la profesora Piacentini indica cómo los versos insertos en la ensalada difieren en mayor o menor medida de la versión incluida en las recopilaciones de textos antiguos de Durán o Primavera. En algún caso el autor de la ensalada habrá modificado versos para hacerlos más a propósito de su intención (seguramente en las dos citas que mencionamos en la.12, tal vez en el 2a.5 más abajo); en otros habrán sido los editores de las versiones impresas los que retocaron las formulaciones de lo que se cantaba para darlo a la imprenta. Pero en muchos casos se tratará de auténticas variantes orales de los siglos xvi y xvir. En la lista de no identificados encontramos también varios casos por el estilo:

1b.1. "Competir con mi tristeza / no puede la de otro triste", del poema de Castillo Solórzano (1625), reaparece cincuenta años más tarde en los Romances varios de diferentes autores (Amsterdam, 1677 y 1688) con la formulación "Competir con mi tristeza / bien puede la de otro triste" 19 .

1b.2. "Día fue muy aziago / muy bien me lo daua el alma", de la Nveua gverra de Joaquín Moreno de Cepeda (fines del siglo XVI), debe ser cita del "Romance a la muerte del rey Bermejo de Granada" que Lorenzo de Sepúlveda incluyó en sus Romances nveuamente sacados de hystorias antiguas de la crónica de España (ediciones de Amberes s.a. y 1566) con el inicio "Día fue muy aziado [sic] ay quel alma me lo daua" ${ }^{20}$.

1b.3. "Llenos de lágrimas tristes / teneys mis ojos amor", de la Glosa peregrina y del Chiste nueuo, es el inicio de un villancico que aparece con la misma formulación en tres manuscritos de entre 1500 y 1520 , donde se atribuye a Pastrana; y como anónimo en el Cartapacio de Padilla. Pero en el pliego Coplas contra las rameras (¿1530?) el inicio es "Llenos de lágrimas tristes / tiene mis ojos Amor". En el Cancionero llamado Flor de enamorados (Barcelona, 1562, con reimpresiones hasta 1681) es "Lleno de lágrimas tristes / tengo mis ojos amor"; y en la Silva de varios romances agora nueva-

${ }^{18}$ Sobre la transmisión oral de textos en los Siglos de Oro véase Frenk 1982 y sobre la oralidad en la lectura, 1986. Sobre distintos aspectos del papel de la oralidad en la literatura de esos siglos puede verse la colectánea de artículos en el número monográfico de Edad de Oro, 7 (1988).

19 Véase Rodríguez Moñino 1973-1978, t. 4, p. 69.

${ }^{20}$ Ibid., t. 2, p. 426. 
mente recopilados (Zaragoza, 1617 y reimpr. 1657, 1658 y 1673) como "Llenas de lágrimas tristes / tengo mis ojos amor" 21.

1b.4. "Solos a que en confesión / que no nos escucha nadie", de la obra de Castillo Solórzano, aparece con diversas variantes en fuentes de finales del siglo xvi y comienzos del XviI: en la Flor de varios romances nueuos. Primera y segunda parte (Barcelona, 1591) es "Solos aquí en confessión / que no nos escucha nadie"; en la Qvarta y quinta parte de la Flor de romances (Burgos, 1592 y 1594) es "Solos aqui en confessión / que no nos escuche nadie", formulación con la que aparece también en el Romancero general de 1600 y 1602; en el Ramillete de flores (Lisboa, 1593) "Solos aquí en confissión / que no nos entienda nadie", lo mismo que en la Sexta parte de Flor de romances nueuos (Toledo, 1594 y sus descendientes bibliográficos de Zaragoza, 1596 y Alcalá, 1597)22.

1c. Composiciones de las que nos han llegado otros textos de los siglos XV al XVII y que han pervivido en la tradición oral hasta época moderna. De entre los romances identificados por Piacentini, unos cuantos (por ejemplo, los números $29,38,45,48,71,72,74,78,81,84$ y 130) han pervivido en la memoria de las gentes hasta época reciente, habiéndose documentado en la tradición oral moderna.

Por otra parte, un buen puñado de las citas del Tercero quaderno no han sido tenidas en cuenta por Piacentini, seguramente por tratarse de fragmentos (a veces bastante largos) de canciones líricas tradicionales que ya habían sido identificadas por Margit Frenk en sus estudios sobre lírica popular y posteriormente han sido incoporados a su monumental Corpus de la lírica: en efecto, la composición empieza con un conocido refrán ("Quien madruga Dios le ayuda / si lleva buena intención") y en boca de sus rústicos personajes se ponen a continuación versos de alguno que otro romance y de varias cancioncillas líricas: "Ay luna que reluces / toda la noche me alumbres", "Cuándo saliréis, alba galana", "Trébole, ay Jesús como huele", "Que no cogeré yo verbena / la mañana de Sant Juan", "A Salamanca el escolanillo / a Salamanca irás", "Yo qué le hice, yo qué le hago / que me da tan ruin pago" y "No sois vos para en cámara, Pedro"'23.

${ }^{21}$ Dutton 1982, núm. 3467; Rodríguez Moñino 1970, p. 682.

22 RodRígueZ MOÑINo 1973-1978, t. 2, p. 768.

23 Véanse respectivamente los números $1072 \mathrm{~b}-\mathrm{c}, 1077 \mathrm{c}, 1252 \mathrm{a}-\mathrm{d}, 522 \mathrm{a}$, 1038 y 644 de Frenk 1987. Con anterioridad al artículo de Piacentini habían sido tratados en Frenk 1966. 
Por otra parte, "Madre una moçuela / que en amores me habló", también del Tercero quaderno (ésta sí en la lista de no identificados), está citado en la ensalada de Praga y Frenk lo pone en conexión con una canción popular andaluza ${ }^{24}$.

En la lista de no identificados hay otros casos interesantes de composiciones que pervivieron en la tradición oral:

1c.1. "Parióme mi madre / una noche oscura", del Tercero qvaderno, es endecha muy popular en los siglos XVı y XVII, que ha pervivido hasta hoy entre los sefardíes como canto de muerte. En cuanto a ediciones antiguas, se publicó en las Silvas de Zaragoza, 1550 y Barcelona, 1550 y 1552 y en el Cancionero llamado Flor de enamorados (Barcelona, 1601, aunque hay noticia de unas ediciones de 1562 y 1573 y se reeditó hasta 1681). Dio pie además a imitaciones y contrafacta, como el "Parióme adrede mi madre" de Quevedo, impreso por primera vez en los Sueños y discursos (Barcelona, 1627) o el "Púsoseme el sol / salióme la luna" de Juan de Salinas. Covarrubias cita los cuatro primeros versos en su $T e^{-}$ soro (1611) s.v. cubrir y endechas. Y alcanzó además eco en el teatro de los Siglos de Oro: lo cantan en Las famosas asturianas de Lope; y es trasfondo del título y tema de la también lopesca Púsome el sol, salióme la luna y de La luna de la sierra de Vélez de Guevara. Se cita además en la ensalada de Praga.

En cuanto a su pervivencia moderna, ya hemos dicho que se da como endecha en Marruecos, con frecuencia unidos los versos que aquí tenemos a formulaciones (quizás también antiguas) que perviven en la lírica andaluza ${ }^{25}$.

le.2. "Muerte que a todos combidas / dime qué son tus manjares", de la Glosa peregrina, es el inicio de un decir que aparece en una decena de manuscritos: se atribuye a Juan de Mena en el Cancionero de don Pedro Antonio de Aragón y en el de Vindel (ambos de ha. 1480). A Diego de Palomeque se lo atribuyen el Cancionero de Román (ha. 1454), el Cancionero de Barrantes y otro de la Universidad de Salamanca (de principios del siglo XVI). Un manuscrito de Montserrat se lo adjudica ai Marqués de Santillana.

${ }^{24}$ Frenk 1987, núm. 260.

${ }^{25}$ Para la aparición en textos impresos, véase Rodríguez MoÑIno 19731978 , t. 2, p. 653 y t. 4, p. 189. Para el poema de Juan de Salinas, cf. Alonso y Blecua 1978, núm. 489. Para el conjunto de versiones, Frenk 1987, núms. 409 y 772. Para las orales modernas, Alvar 1969, núms. Xlla-c y, sobre todo, el importante estudio (con atención también a los textos antiguos) de pp. 59-68. 
Y aparece como anónimo en otros cuatro (el más antiguo, de 1440).

Está también en el pliego (de ha. 1530) Coplas de la muerte como llama a un poderoso Cauallero y otras coplas a la muerte y otras coplas hechas por Juan del Enzina, de la Biblioteca Nacional de Madrid, que contiene: a) un poema anónimo que empieza "Duermes o velas portero" y cuyo contenido recuerda al de las Danzas de la Muerte, ya que describe la discusión entre un innominado Caballero y la Muerte que viene a llevarle; $b$ ) el poema "Muerte que a todos convidas"; $c$ ) un par de villancicos; y d) unas coplas de Juan del Encina que nada tienen que ver con el tema mortuorio, aunque la mención de este autor en el encabezamiento del pliego haya hecho que en algún caso se le hayan atribuido las Coplas de la muerte iniciales ${ }^{26}$.

Lo más apasionante del caso es que en la tradición sefardí de Marruecos se ha recogido (por primera vez en 1905, por última hará menos de una década) un canto para endechar a los muertos que funde: a) el inicio de "Muerte que a todos convidas"; b) buena parte del contenido de las anónimas Coplas de la muerte y c) otros elementos, ausentes de uno y otro texto. Además, de la tradición oriental se conoce otra endecha, impresa en un librico aljamiado de cantos luctuosos de Esmirna, que presenta semejanzas con el poema marroquí (y tal vez derive de él) ${ }^{27}$.

El origen y la formación de la endecha de Marruecos ha sido objeto de amplia controversia: cuando Menéndez Pidal y José Benoliel publicaron la primera versión, calificaron el poema como "de inspiración propiamente hebraica" ; más tarde, al estudiarlo Manuel Alvar, demostró su origen hispánico y afirmó: "creo que el hallazgo de este pliego [el de la Biblioteca Nacional] autoriza a pensar que los judíos, si no lo conocieron, usaron alguno semejante que contendría, quizás, otros poemas', dando por supuesto que la fusión del inicio del poema de Mena con las coplas del Caballero y la Muerte se habría producido en el siglo XVI. Pero, al reseñar el libro de las Endechas de Alvar, Paul Bénichou insinuaba la mayor modernidad de la fusión de esos elementos y de la incorporación del tema al repertorio marroquí,

${ }^{26}$ El propio Rodríguez Moñino 1970, p. 684 lo recoge como obra de Encina. Para versiones manuscritas, cf. DutTon 1982, núm. 0510.

27 La primera versión sefardí la publicaron Menéndez Pidal y Benoliel 1905. El texto sefardí de Oriente fue estudiado por Armistead y Silverman 1968-1969, reimpreso en 1982, pp. 89-95. 
con la posibilidad de que "hubiera existido alguna reimpresión de esos poemas" y que "los judíos de Marruecos hubieran podido conocerla durante el siglo XIX" 28 .

Así pues, la mención en la Glosa peregrina de esos versos de Muerte que a todos convidas nos testimonia que el poema estaba vivo en la memoria del autor (y de los lectores) de la ensalada todavía treinta años después de la impresión del pliego. Pero supone una referencia tantálica, que nos deja en los labios la miel de poder resolver el origen del canto de muerte sefardí: ¿qué era lo que conocía el autor de la Glosa peregrina? ¿Simplemente el poema "Muerte que a todos convidas" atribuido a Mena y Palomeque? ¿O, todavía más, un poema prototipo de las versiones sefardíes que uniese, ya en el siglo xvI, el inicio de "Muerte..." con las Coplas y con esos otros elementos de desconocido origen presentes en la endecha judeoespañola?

En otras palabras: ¿se había producido ya en 1560 la fusión de elementos que se manifiesta en la endecha marroquí? Convendría hacer un cotejo cuidadoso entre las distintas versiones manuscritas, la del pliego y las sefardíes en busca de paralelos y diferencias que pudieran ayudarnos'a desentrañar cuándo se produjo la fusión de elementos que encontramos en las versiones orales modernas. Es tarea que no renuncio a emprender algún día, ahora que contamos con un exhaustivo repertorio de cancioneros manuscritos.

\section{Composiciones que no aparecen en otras fuentes antiguas}

2a. Las que debieron'gozar de popularidad en su momento, pero de las que no se nos han conservado textos. Son citas que documentan temas romancísticos y cancioneriles que sin duda gozaron de popularidad en su momento, pero que hoy nos resultan desconocidos por no haber tenido la fortuna de ser recogidos en algún escrito conservado. De entre ellos, podemos especular sobre el posible carácter y contenido de varios:

${ }^{28}$ Fue en efecto Alvar 1969 el primero en poner en conexión el pliego con el poema sefardí: edita tres versiones de la endecha judeoespañola (textos $\mathrm{Xla}-\mathrm{c}$ ), analiza la relación de los textos sefardíes con el pliego suelto (capítulo 5, pp. 45-58) y reproduce en Apéndice las Coplas de la muerte del pliego suelto (pp. 183-192) con variantes de un manuscrito del siglo xV. Véase también la edición de dos textos más, con notas, en Díaz-MAS 1982, pp. 303-332. Es importante el artículo reseña a Alvar de BéNICHOU 1960. 
2a.1. "Cantauan las aues mi mal / por desierto y poblado", del Tercero quaderno, puede ponerse en conexión con una cita del Abecedarium: "Francisci de Armentia. Glosa en coplas sobre el romance de Yanguás que comienza Canten las aves mi mal' 29

2a.2. "La riña de por Sant Joan / es paz para todo el año", de la Glosa peregrina, es refrán recogido por Correas. Pero recordemos que además se incluye en la cancioncilla final del entremés cervantino $E l$ juez de los divorcios (publicado en 1615). La cita de la ensalada ¿ ¿ se referirá al refrán o a alguna canción que a su vez lo citase y en la que pudo inspirarse Cervantes para su fin de fiesta entremesil?

2a.3. "Los brazos lleua cansados / dela cruz sobrel llevar", igualmente de la Glosa peregrina, podría pertenecer a alguna versión a lo divino del romance de La muerte de don Beltrán ("Por los campos de Alventosa" o "Por la matanza va el viejo"), ya que parece contrafactum de la formulación de ese romance "Los brazos lleva cansados / de los muertos rodear"'30.

2a.4. "Triste flaco y amarillo / y de la vida cansado", de la Vida del estudiante pobre: las palabras iniciales y la asonancia en -áo nos hacen pensar en una cita paródica o en un contrafactum de un romance sobre el robo de Elena que veinte años antes había publicado Timoneda en su Rosa 'gentil: "Triste, afligido y pensoso / estaua el rey Menelao"31.

2a.5. Algo parecido puede decirse de "Y a caça como solía / llegó hasta Almería", del Tercero quaderno, donde, para empezar, extraña que rimen ambos hemistiquios; y, por otro lado, en el primero podemos ver un eco del "A cazar va el caballero / a cazar como solía" que es inicio habitual del romance de La infantina. ¿Será cita de algún contrafactum o el autor de la ensalada habrá modificado la formulación romancística para adaptarla a sus necesidades? ${ }^{32}$.

2b. Composiciones de las que no se conservan textos antiguos, pero sí tradicionales modernos. Más interesantes aún resultan tres citas pertenecientes a sendos romances de los que no se han conservado ver-

${ }^{29}$ Rodríguez MoÑino 1970, p. 660. La relación con la cita del Abecedarium la señala el mismo RodRíguez MoÑino 1976, p. 237.

${ }^{30} \mathrm{El}$ romance es el núm. 185 y 185 a de Primavera y 395 de Durán.

31 Rodríguez MoÑino 1973-1978, t. 2, p. 785.

${ }^{32}$ El romance es el de Primavera, núm. 151 y Durán 295. 
siones antiguas, pero que han pervivido en la tradición oral moderna.

2b.1. "Cata las sierras de ardeña / donde brama vn animal", de la Glosa peregrina, ha sido identificado por S. G. Armistead y J. H. Silverman como un verso del romance de Celinos y la adúlte$r a$, del cual se han recogido versiones orales modernas castellanas, portuguesas, sefardíes orientales y una ibicenca. El verso en cuestión, con la mención de los montes de Ardenne (aquí Ardeña) no aparece en los textos modernos del romance, pero sí en su originario francés: la Chanson de Beuve de Hantone, del siglo XII; por tanto, la cita vendría a documentar en el siglo XVI una formulación del cantar medieval que no ha pervivido en la tradición moderna, pero que sin duda estaba en versiones del romance del siglo XVI, de las cuales no nos ha llegado más que la sucinta cita de la Glosa33.

2b.2. "De dónde benides Zid / que en cortes no abéis estado?", incluido en la Glosa de muchos rromanzes (de comienzos del siglo XVII), es el número 126 de la lista de Piacentini. No andaba descaminada la autora al identificarlo (con interrogaciones) como "una versión desconocida de Por Guadalquivir arriba". En efecto, alguna relación tiene con ese romance cidiano: se trata del inicio de El destierro del Cid, tema romancístico que ha sido definido por Paul Bénichou como "una especie de centón de citas o recuerdos tradicionales", que integra el inicio de Por Guadalquivir. . con citas y situaciones de otros romances del Cid (como Cabalga Diego Laínez o En santa Gadea de Burgos) o de Bernardo del Carpio (Con cartas y mensajeros), además de algún elemento de otros romances de carácter más o menos épico o fronterizo (Por las almenas de Toro, Bobalías). Los únicos textos que conocemos son de la tradición oral, especialmente de la sefardí de Marruecos, aunque alguna versión hay también de la isla de Madeira, de los sefardíes de Yugoslavia y de la tradición andaluza, además de algunas versiones tradicionales a lo divino castellanas y extremeñas.

La cuestión de sus orígenes y antigüedad ha sido objeto de discusión: mientras que Bénichou afirma que "la elaboración

33 Véase al respecto el estudio de Armistead y Silverman 1982, pp. 3542 , que es a su vez refundición de un artículo publicado en la NRFH, 25 (1976), 86-94. En el mismo libro de 1982, pp. 83-88, estudian una de las ensaladas despojadas por Piacentini (la de Castillo Solórzano) tomándola como base para documentar variantes antiguas del romance de Tarquino y Lucrecia. 
compleja y acertada que produjo el Destierro del Cidies seguramente muy antigua" y que

todo indica que... fue creado cuando estaban todavía vivos en las memorias los textos poéticos y datos legendarios de la tradición épica de España, es decir, en un tiempo relativamente próximo a la época de poetización inicial en la cual nació el romancero viejo.

Diego Ciatalán defiende, por el contrario, que "todo inclina a pensar que se compuso en pleno siglo xvı y que su tradicionalidad nada tiene que ver con la del romancero medieval de inspiración épica" 34 .

Sea como sea, y pese a no habérsenos conservado textos antiguos, El destierro del Cid debió gozar de bastante popularidad a comienzos del siglo XVII (no nos consta que antes): no sólo aparece en nuestra ensalada, sino que su incipit está en otra incluida en el cartapacio (también de la primera mitad del XVII) de Pedro de Penagos, que se conserva en la Biblioteca de Palacio de Madrid. Además, Góngora cita el hemistiquio "que en cortes no habéis estado" en una décima incluida en la edición de sus Obras (Madrid, 1627) y Lope alude a un pasaje del romance en La pobreza estimada (publicada en la Parte 18 de sus comedias, Madrid, 1623) ${ }^{35}$.

2b.3. En cuanto a "Tristes nueuas dolorosas / se suenan por toda España', de Vida del estudiante pobre, en vano habrá buscado la profesora Piacentini un verso semejante en colecciones de textos antiguos: el verso pertenece, sí, a un romance viejo, pero cuyo inicio nos es conocido exclusivamente a través de versiones orales modernas: el que narra la Muerte del principe don Juan, primogénito de los Reyes Católicos, ocurrida en 1497 y que debió de ser compuesto a raíz del suceso.

No obstante su indudable antigüedad, no se conserva ninguna versión escrita de los Siglos de Oro. La primera versión conocida es una portuguesa recogida de la tradición oral por Almeida Garret a finales del siglo xIx; a principios del xx María Goyri identificó el tema en un fundamental artículo; y más modernamente lo ha estudiado Paul Bénichou, tratando de reconstruir las características de las perdidas versiones antiguas sobre la base de

${ }^{34}$ Son fundamentales los estudios de Bénichou 1968, pp. 13-39 y CATALÁN 1970-1971, pp. 458-461. Las citas provienen de esos dos artículos. Véanse el análisis del romance con reseña de todas las versiones orales conocidas en Catalán 1983, t. 2, núm. 18.

${ }^{35}$ Los datos son del artículo de Catalán 1970-1971. 
las orales modernas ${ }^{36}$. El único testimonio anterior al siglo xIX son tres versos interiores citados por Vélez de Guevara en un parlamento de su comedia La serrana de la Vera (1613), que vienen a testimoniar la vida oral del romance a comienzos del siglo xVII: "Siete dotores lo curan / y entre ellos el de la Parra", "Muy malo está vuestra alteza / don Juan Príncipe de España" y "tres horas tenéis de vida / y la una ya se pasa".

El verso de la Vida del estudiante pobre es sin duda el primero del romance, ya que en la tradición oral moderna son habituales los inicios del tipo "Tristes nuevas, tristes nuevas / que se cuentan por España”, “. . . / que se corren por España”; o, en versiones portuguesas, "Tristes novas, tristes novas / em Espanha foram soadas", etc.; y, seguramente por eufemismo, también se dan los inicios "Cosas buenas, cosas buenas / que se cuentan por España", "Lindas nuevas, lindas nuevas, / qué se cuenta por España", etcétera.

Esos inicios, con la mención de las malas noticias, conviven con otros que anuncian de entrada la enfermedad del príncipe ("Muy malo estaba don Juan / muy malo estaba en la cama", "Hazino está el hijo del rey / hazino que no salvaba", etc.) o con el típico en Marruecos, en que se introduce una especie de prólogo con un fatídico viaje y una carta de mal augurio ("De Burgos partióse el rey / de Burgos a Salamanca // y en la mitad del camino / del cielo cayó una carta"37.

El interés de la cita de la ensalada radica, pues, en dos aspectos: a) ser el "texto" (mínimo, pero texto al fin) más antiguo del romance de la Muerte del príncipe don Juan conocido hasta ahora; y $b$ ) atestiguar la antigüedad del inicio del tipo "Tristes nuevas..." , hasta hoy sólo documentado en versiones orales castellanas y portuguesas modernas: ¿comenzaría justamente así el romance compuesto a finales del siglo xv y serán los otros inicios creación más tardía?

Estas pocas muestras, unidas a lo ya señalado en su artículo por la profesora Piacentini, vienen a poner de relieve lo que ya indicábamos al principio: la enorme rentabilidad del esfuerzo in-

${ }^{36}$ La primera versión portuguesa la incluyó TeófILo Braga en su Romanceiro Geral (Coimbra, 1867), pp. 55 y 190. Véanse los estudios de GoYri 1904 y BÉNıCHOU 1963, este último reimpreso en 1968, pp. 95-124.

${ }^{37}$ El romance está analizado a través de todas sus versiones en GATALÁN 1983 , t. 3, núm. 70. Véase especialmente la lista de incipit modernos en pp. 432-433; los indicados en p. 432 como incipit antiguos son los tres versos de la obra teatral de Vélez de Guevara. 
vertido en rastrear textos de los siglos XVI y XVII en busca de reminiscencias de una poesía que -independientemente de sus orígenes cultos - debió tener en esos siglos una activa vida oral y que nos es conocida sólo a través de los testimonios que azarosamente nos han llegado (por inclusión ocasional y más o menos manipulada en colecciones poéticas manuscritas o impresas, por pervivencia en la tradición oral moderna, por haber sido citada o aludida en otros géneros poéticos o en la narrativa o en el teatro).

Pero la mayor utilidad de esa rebusca tal vez no sea siquiera detectar las ocurrencias de un incipit antiguo, entrever la vida oral de un tema poético en los Siglos de Oro a través de las variantes que presenta en las distintas fuentes, o documentar la vetustez de determinada composición que ha pervivido en la tradición moderna. Más interesante que todo eso es sin duda cómo, a raíz de estos estudios, se pone de relieve la necesidad de estudiar como un continuum tres parcelas que hasta ahora han estado demasiado consideradas como compartimentos estancos: 1) la poesía cancioneril (y, desde luego, el romancero) del siglo xV; 2) la de la siglos XVI y XVII, nos haya llegado a través de cancioneros y romanceros manuscritos o impresos o de pliegos sueltos; y 3) la que hasta hace pocas décadas se ha mantenido vigente en la tradición oral.

Hemos visto cómo buena parte de las composiciones citadas una y otra vez en ensaladas de los Siglos de Oro tienen su origen no sólo en el Romancero viejo, sino en la poesía cancioneril del siglo $\mathrm{xv}$; y cómo algunos de esos temas han permanecido vivos hasta fechas recientes en boca de cantores populares. Los Siglos de Oro se revelan una vez más como una época bisagra en la que ciertos géneros de origen cortesano se divulgan a un público urbano más amplio. En el caso de ciertos tipos de poesía esa divulgación puso a veces en marcha un proceso de transmisión oral, que en ocasiones ha llegado hasta el siglo xx.

De ahí que: a) la poesía del siglo xv no pueda entenderse cabalmente sin tener en cuenta su continuidad y pervivencia en siglos posteriores; $b$ ) la de los Siglos de Oro sea inconcebible sin considerar lo que hereda de la medieval, ya que una parte de la poesía más popular —en el sentido de conocida y aceptada por un amplio público- de los siglos XVI y XVII proviene de la última época de la Edad Media, aunque sea reinterpretada al gusto de los nuevos tiempos (por ejemplo, reescribiéndola en glosas, contrafacta a lo divino o incluso en las mismas ensaladas); y 
c) resulte imprescindible considerar la tradición oral moderna en relación con la poesía de los siglos XV al XVII, y no sólo porque muchos temas tradicionales tienen su origen precisamente en esos siglos, sino porque la consideración de lo que pervivió en la transmisión oral arroja en muchas ocasiones luz sobre lo antiguo: sobre sus contenidos y sobre sus modos de transmisión.

Paloma Díaz-Mas Universidad del País Vasco

\section{BIBLIOGRAFIA}

Alonso, Dámaso, y José Manuel Blecua 1978. Antología de la poesía española: lírica de tipo tradicional. Gredos, Madrid.

Alvar, Manuel 1969. Endechas judeo-españolas. C.S.I.C., Madrid.

Armistead, S. G., y J. H. Silverman 1968-1969. "Las Colpas de la Muerte como llama a vn poderoso Cauallero y una endecha judeo-española de Esmirna', $A L M, 7,171-179$.

- 1982. En torno al romancero sefardi (Hispanismo y balcanismo de la tradición judeo-española). Seminario Menéndez Pidal, Madrid.

BÉnichou, P. 1960. "El cancionero lírico-español de Marruecos", NRFH, 14, 97-102.

- 1963. "Variantes modernas en el romancero tradicional: sobre la Muerte del Principe D. Juan", RPh, 17, 235-252.

- 1968. Creación poética en el romancero tradicional. Gredos, Madrid.

Bernardach, M. 1973. "Castillo Solórzano et ses fantaisies prosodiques (À propos d'une ingénieusse utilization des romances)", $R L R, 80,149-175$.

BlecuA, J. M. 1983. "Un interesante cancionero del siglo XVI: el manuscrito 3902 de la Biblioteca Nacional de Madrid", en Serta Philologica F. Lázaro Carreter. Cátedra, Madrid, t. 2, pp. 67-90.

Catalán, D. 1970-1971. "Memoria e invención en el Romancero de tradición oral", $R P h, 24,1-25$ y 441-463.

- et al. 1983. Catálogo general del Romancero. Gredos, Madrid.

Cátedra, Pedro M., y Víctor Infantes 1983. Los pliegos sueltos de Thomas Croft (Siglo xvi). Albatros, Valencia.

Díaz-MaS, Paloma 1982. Temas y tópicos en la poesía luctuosa sefardí. Universidad Complutense, Madrid.

— 1988. "Dos versos enigmáticos en un contrafactum romancístico de Castillejo", RDTP, 42, 211-217.

Duran, Agustín 1926, 1930. Romancero general o Colección de romances castellanos anteriores al siglo xviii... BAE, ts. 10, 16.

DutTon, Brian et al. 1982. Catálogo-índice de la poesía cancioneril del siglo xv. Madison, 2 ts.

FRenK, Margit 1966. Lírica española de tipo popular. UNAM, México.

- 1982. "Lectores y oidores. La difusión oral de la literatura en el Siglo de Oro', $C H(7)$, 1, pp. 101-123. 
Frenk, Margit 1986. "La ortografía elocuente (Testimonios de la lectura oral en el Siglo de Oro)", $C H(8)$, pp. 549-556.

— 1987. Corpus de la antigua lírica popular hispánica (siglos xv al xvii). Castalia, Madrid.

— (ed.) 1989. Villancicos, romances, ensaladas y otras canciones devotas de Fernán González de Eslava. El Colegio de México, México.

Goyri, M. 1904. "Romance de la muerte del príncipe don Juan (1497)", BHi, 6, 29-37.

INFANTES, V. 1989. "Edición, literatura y realeza, apuntes sobre los pliegos poéticos incunables", en Literatura hispánica, Reyes Católicos y Descubrimientos. Actas del Congreso Internacional. . P.P.U., Barcelona, pp. 85-98.

MenÉndez PIdal, Ramón 1953. Romancero hispánico (hispano-portugués, americano y sefardí). Espasa-Calpe, Madrid, 2 ts.

- y J. Benoliel 1905 . "Endecha de los judíos españoles de Tánger", $R A B M, 12,128-133$.

Primavera: Fernando José Wolf y Conrado Hofmann, Primavera y flor de romances, Berlín, 1856, 2 ts. Reed. por M. Menéndez Pelayo, Antología de poetas líricos castellanos, ts. 6-9, C.S.I.C., Madrid, 1945 (Obras completas de Menéndez Pelayo, ts. 22-25).

Rodríguez Moñino, Antonio 1969. "Tres cancioneros manuscritos (Poesía religiosa de los Siglos de Oro)", Ábaco: estudios sobre la literatura española 2. Castalia, Madrid, pp. 127-272.

— 1970. Diccionario bibliográfico de pliegos sueltos poéticos (siglo xvi). Castalia, Madrid.

-1973-1978. Manual bibliográfico de cancioneros y romances. Castalia, Madrid, 4 ts.

— 1976. La transmisión de la poesía española en los Siglos de Oro. Ariel, Barcelona. 